\title{
O SETOR DE HOTELARIA DA PRAIA DE CANOA QUEBRADA-CE FRENTE A PANDEMIA DA COVID-19
}

\author{
A. F. N. VALE ${ }^{1}$, S. V. DA C. REGIS, N. I. F DOS SANTOS, A. M. B. DE OLIVEIRA \\ Universidade Federal Rural do Semi-Árido \\ ORCID ID: https://orcid.org/0000-0001-5876-47301 \\ alinefrancilurdes@hotmail.com ${ }^{1}$
}

Submetido 24/07/2020 - Aceito 17/09/2020

DOI: $10.15628 /$ holos. 2020.10818

\section{RESUMO}

O objetivo deste artigo é analisar como a gestão hoteleira de Canoa Quebrada-CE está vivenciando o contexto da pandemia da Covid-19. Com isso em mente, buscou-se compreender o impacto da pandemia nos negócios de hotelaria e identificar as ações adotadas e/ou planejadas pelas organizações para se adaptar ao novo cenário. Trata-se de uma pesquisa de abordagem qualitativa, do tipo descritiva. Para tanto, foram realizadas entrevistas com oito representantes do setor hoteleiro de Canoa
Quebrada-CE. Com base na Análise de Conteúdo de Bardin (2006), observou-se que os gestores estão assumindo um comportamento pouco prospectivo, reagindo ao ambiente de incerteza e de perda de receita apenas em última instância e quando forçados a tomarem decisões estratégicas. Este estudo contribui para a análise e discussão de um tema emergente, que representa um marco social e econômico para o setor hoteleiro e para a economia mundial.

PALAVRAS-CHAVE: Pandemia, Covid-19, Gestão hoteleira, Canoa Quebrada, Comportamento estratégico.

\section{THE HOTELS OF PRAIA DE CANOA QUEBRADA-CE FRONT OF THE PANDEMIC OF COVID-19}

\begin{abstract}
The objective of this article is to analyze how the hotel management of Canoa Quebrada-CE is experiencing the context of the pandemic of the Covid-19. In view of this, we sought to understand the impact of the pandemic on the hotel business and to identify the actions adopted and / or planned by the organizations to adapt to the new scenario. This is a qualitative, descriptive research. To this end, interviews were conducted with eight representatives of the Canoa Quebrada-CE sector hotel.
\end{abstract}

Based on Bardin's Content Analysis (2006), it was observed that managers are assuming little prospective behavior, reacting to the environment of uncertainty and loss of revenue only as a last resort and when forced to make strategic decisions. This study contributes to the analysis and discussion of an emerging theme, which represents a social and economic framework for the hotel sector and the world economy.

KEYWORDS: Pandemic, Covid-19, Hotel management, Canoa Quebrada, Strategic behavior. 


\section{INTRODUÇÃO}

O estado do Ceará abarca uma grande variedade de destinos turísticos, incluindo praias, serras e o sertão, movimentando o segmento do turismo o ano inteiro. De acordo com dados da Pesquisa Mensal de Serviços (PMS), fornecidos pelo Instituto Brasileiro de Geografia e Estatística (IBGE), o Ceará apresentou o maior crescimento em atividades turísticas $(5,4 \%)$ em comparação com os outros 12 estados avaliados, entre os meses de janeiro e novembro de 2019 (Fecomércio, 2020).

De forma mais específica, um dos locais fomentadores do turismo no estado é a praia de Canoa Quebrada que fica localizada no litoral leste do Ceará, no município de Aracati; distante 12 $\mathrm{km}$ da cidade e $165 \mathrm{~km}$ da capital do estado; possui sua origem relacionada ao mar que exerce considerável participação nas atividades econômicas e culturais da região. Nesse ínterim, o crescimento da atividade turística em Canoa Quebrada colocou o município de Aracati entre um dos 65 destinos indutores do Brasil, devido ao seu belo cenário e as animadas noites com diferentes estilos musicais, atraindo turistas das mais diversas localidades, tornando-a um espaço turístico urbanizado (Siqueira, Urano, \& Pereira, 2017).

Contudo, Tomé (2018) explica que o setor de hotelaria é expressivamente afetado pelas conjunturas e tendências nacionais e internacionais. Isso pode ser comprovado com o surgimento da Covid-19, doença que surgiu na China; no final de 2019 e logo se espalhou pelo mundo, causando mortes e infectando inúmeras pessoas; sendo posteriormente declarada pela Organização Mundial da Saúde (OMS, 2020) como uma pandemia de interesse internacional. Com esse panorama, governos de todo o mundo passaram a adotar drásticas medidas de contenção, como quarentena e isolamento social, com vistas a combater a propagação do vírus.

Essas ações ocasionaram a suspensão de viagens e o fechamento de fronteiras; demarcando uma recessão econômica comparada apenas às das crises decorrentes das guerras mundiais do século XX (Baum \& Hai, 2020). Tal recessão impacta sobremaneira o setor no país, posto que reduz drasticamente a demanda por serviços turísticos e hoteleiros. Conforme o levantamento apresentado pela Cielo, "Serviços - Turismo e Transporte" houve um declínio de 74\% nos meses de março, abril e maio de 2020, em relação ao mês de fevereiro deste mesmo ano (Lafis, 2020). Da mesma forma, segundo o Serviço Brasileiro de Apoio às Micro e Pequenas Empresas (Sebrae, 2020a), houve uma queda de $89 \%$ no faturamento do setor no período de março deste ano. Esse número, é resultado do fechamento de estabelecimentos e da mudança de comportamento do consumidor que cumpre o isolamento social.

De acordo com dados do IBGE (2020), com o surgimento da pandemia da Covid-19, em abril de 2020 , o volume de atividades turísticas apresentou uma redução de 54,5\% em relação a março de 2019, resultando na maior queda no setor desde 2011. As medidas adotadas como isolamento social e quarentena, atingiram de forma mais evidente empresas que compõem as atividades do turismo, como transporte aéreo, restaurantes e hotéis. Em relação a abril de 2019 , essa retração foi de $67,3 \%$ e deu-se devido à queda de quase $R \$ 90$ bilhões nesses segmentos. 
O setor de turismo e hotelaria é vulnerável a crises e a desastres porque se baseia em infraestrutura, capacidade de se movimentar livremente e na percepção de segurança das pessoas (Akron et al., 2020; Brown et al., 2017; Ritchie \& Jiang, 2019). Por isso, precisa estar preparado para administrar acontecimentos inesperados que impactam o ambiente de negócios e que ameaçam a viabilidade e lucratividade do setor. Para tanto, as organizações desse segmento devem considerar muitos fatores e condições antes de elaborar uma estratégia, com vistas a se adaptarem aos tempos difíceis e sobreviverem no mercado. Com isso em mente, seus gestores podem se basear em experiências passadas ou fazer prospecções inusitadas para superarem as crises atuais e até mesmo se prepararem melhor para as crises futuras (Kim, Rohl, \& Lee, 2019).

Quanto a essa questão, uma busca na Web Off Science mostrou que existem vários estudos com foco em estratégias organizacionais em momentos de crises no setor de turismo e hotelaria (Cor \& Martins, 2017; Dá-Ihes \& Susilowati, 2015; Novelli et al., 2018; Ritchie \& Jiang, 2019; Zopiatis et al., 2019). No entanto, há incipientes pesquisas que abarcam os impactos da pandemia da Covid19 no setor, especificamente por ser uma temática emergente, porém recente e atual. É importante ressalvar que a diminuição do fluxo de turistas nacionais e internacionais representa um impacto social e econômico drástico para o setor hoteleiro e para a economia mundial. Em vista disso, indaga-se: como a gestão hoteleira de Canoa Quebrada está vivenciando esse contexto de pandemia? Para responder a problemática proposta, pretendeu-se compreender o impacto da pandemia nos negócios de hotelaria e identificar as ações adotadas e/ou planejadas por essas organizações para se adaptar ao novo cenário.

\section{REVISÃO BIBLIOGRÁFICA}

\subsection{A estratégia organizacional}

Uma das maiores preocupações das organizações em relação a sobrevivência em um ambiente de negócios turbulento e de constantes mudanças é a criação de uma estratégia organizacional (Köseoglu et al., 2019). No contexto da administração, os conceitos utilizados referentes a estratégia tornaram possível o desenvolvimento da literatura que apresenta a dinâmica em que é utilizada. Assim, segmentos como a direção organizacional, o futuro construído sustentado em ações coletivas e os processos que convergem para o desenho da estratégia, representam desafios para o estudo organizacional, de uma forma geral; e, de uma forma particular, para o estudo da estratégia. Nesse sentido, as "escolas clássicas de estratégia" têm seus argumentos fundamentados em premissas que em alguns casos são válidas e em outros foram avaliadas (Hidalgo, Ramírez, \& Ríos, 2014).

No âmbito etimológico o termo estratégia consiste em estratégias de guerra, porém essa definição se adaptou a realidade das organizações e ao seu entorno, onde existe uma competição acirrada e a vantagem competitiva é almejada. Assim, aquelas que têm a melhor estratégia têm maiores chances de obter sucesso. A necessidade de criar estratégias acompanha a evolução humana durante toda a história e tem evoluído assim como a inteligência humana (Henz, 2014). 
Quando bem-sucedidas, as estratégias proporcionam vantagem competitiva às empresas. No entanto, por si só, as estratégias não constituem garantia de sucesso, para isso, é preciso muitas outras táticas. A vantagem competitiva pode acontecer somente em uma parte do negócio, como atendimento, formas de pagamento, descontos, variedades de produtos, prazo de entrega ou pode ser um processo lógico e estruturado. Mesmo abrangendo apenas uma parte, quando colocada em prática, produz benefícios organizacionais e consolidam boas razões para o consumidor escolher comprar em uma determinada empresa e não na sua concorrente (Oliveira, 2014).

Wright, Kroll e Parnell (2009) definem estratégia como aquilo que se refere ao resultado do planejamento da alta administração para se obter resultados alinhados a missão e aos objetivos da organização. Enquanto administração estratégica é mais amplo, pois abrange os estágios iniciais de análise; tanto do ambiente externo quanto interno, que determinam a missão e os objetivos da organização; como também os estágios finais de implementação e avaliação. A administração estratégica torna-se ainda mais essencial em contextos em que a concorrência se intensifica e em períodos em que a influência do governo nas empresas é maior.

Nesse sentido, o maior desafio que os gestores podem enfrentar é o da administração estratégica; pois, administrar uma organização complexa em um ambiente em constantes mudanças exige as melhores decisões possíveis. As questões que envolvem a administração estratégica possuem ambiguidade e a forma como a organização se relaciona com essas questões define seu sucesso. A administração estratégica representa um desafio, pois ela não é somente estabelecer objetivos e designá-los aos membros da organização, vários aspectos estão envolvidos como a avaliação por parte da alta administração das oportunidades e ameaças que o ambiente externo oferece e a análise dos pontos fortes e fracos da empresa. Sem esquecer de considerar os interesses dos seus stakeholders, uma vez que seu apoio é de fundamental importância para se obter estratégias de sucesso (Wright et al., 2009).

O planejamento do futuro de uma organização tem feito com que o setor responsável pela estratégia organizacional tenha que recorrer a extensas etapas de planejamento estratégico. A pressão para se obter o maior controle e previsibilidade possível dificulta o planejamento em ambientes incertos. Assim, aqueles responsáveis pelo planejamento estratégico devem estar preparados para enfrentar as mais diversas realidades. Dessa forma, ferramentas tradicionais de análise e previsão, e de controle de ações estratégicas tornam-se insuficientes (Hidalgo et al., 2014).

A lógica do processo contínuo de Drucker (2016) parte da ideia de que as decisões estratégicas devem ser planejadas de maneira sistemática, com o maior conhecimento possível do que possa acontecer no futuro, organizando esforços necessários para implementá-las na prática. Para tanto, o planejamento estratégico deve ser visto como um processo contínuo necessário para a organização se manter viva e não ser um acontecimento anual do qual as pessoas desejam se livrar logo, acreditando que as operações e problemas atuais é o que realmente importa (Swaim, 2011).

Ao se tratar de destinos turísticos a competitividade, que consiste na capacidade de um local oferecer um serviço melhor que o outro, é algo cada vez mais desafiador, devido à complexidade desse fenômeno. Esse tema atrai atenção de autores relacionados ao turismo, refletindo como uma importante característica para garantir o sucesso de um destino turístico (Sette \& Tomazzoni, 2017). 
No entanto, Rendón, Martínez e Flores (2014) afirmam que a concorrência no setor de turismo e hotelaria dificulta o estabelecimento de estratégias para alcançar um posicionamento favorável dentro do ambiente de negócios. Isso, por sua vez, tem levado o setor a realizar estratégias de diferenciação, uma vez que essa é uma das principais motivações que influenciam a competitividade nesse setor.

Em momentos de crise e incertezas, como o que está sendo vivenciado, além de representar um desafio maior, torna-se fundamental uma postura de planejamento e gerenciamento mais proativa do que reativa. Nesse sentido, ressalta-se que existem quatro tipos de comportamentos estratégicos que variam de acordo com o grau de incerteza e complexidade do ambiente organizacional, quais sejam: prospector, defensivo, analítico e reativo (Miles et al., 1978). A maneira como o gestor percebe esse contexto no qual a organização está inserida e, a partir de então toma decisões estratégias para alcançar competitividade no mercado, indica o tipo de comportamento que ele assume (Almeida, Antonialli, \& Amiralva, 2010).

O comportamento prospector constitui-se na tendência a ser um inovador, pois o gestor enxerga as mudanças que ocorrem no ambiente organizacional como oportunidades para maximizar os lucros, sendo aquele que parte na frente, como pioneiro. Já o defensivo apresenta uma atitude mais conservadora, reagindo de forma a otimizar seus processos produtivos, oferecendo, por exemplo, preços competitivos ou uma qualidade nos produtos e serviços superior ao de seus concorrentes. O analítico é uma mistura do defensivo com o prospector, procurando reduzir os riscos, mas sem deixar passar as oportunidades de maximizar os lucros; por isso, em geral ele segue o prospector, depois de avaliar sua eficácia. Por último o comportamento reativo, como o próprio nome sugere é aquele que reage às pressões ambientais somente em última instância, ou seja, é inflexível a mudanças e não possui estratégias consistentes que possam auxiliá-lo a enfrentar um ambiente de incertezas, portanto, é resistente em tomar decisões (Almeida et al., 2010; Bertucci, 1999; Chaimankong \& Prasertsakul, 2018; Giménez et al., 1999; Miles et al., 1978; Pletsch et al., 2015).

\section{METODOLOGIA}

Para responder a problemática deste estudo, optou-se por realizar uma pesquisa de abordagem qualitativa do tipo descritiva (Cervo \& Bervian, 2002; Prodanov \& Freitas, 2013). Como instrumento de coleta de dados, utilizou-se uma entrevista não estruturada, para compreender o impacto da pandemia nos negócios de hotelaria e identificar as ações adotadas e/ou planejadas pelas organizações para se adaptar ao novo cenário.

Foram disponibilizados pela Prefeitura de Aracati/CE uma lista com contatos de pousadas e hotéis de Canoa Quebrada. Dessa lista, após vários contatos via telefone, oito representantes da rede hoteleira de Canoa Quebrada aceitaram participar desta pesquisa. Em virtude da pandemia, e restrições quanto ao isolamento social, as entrevistas foram realizadas por meio do aplicativo WhatsApp, de forma que os sujeitos pudessem discorrer livremente a respeito do assunto abordado. A coleta de dados ocorreu no período de 19 a 26 de junho. 
No que tange a análise dos dados, foi utilizada a Análise de Conteúdo de Bardin (2006). Como tal, as fases da análise do conteúdo se subdividiram em: (1) pré-análise, (2) exploração do material e (3) tratamento dos resultados, inferência e interpretação. Na primeira fase, ocorreu a leitura das entrevistas colhidas. Na segunda fase, a organização dos textos e agrupamento destes. E por último, as inferências e interpretação do material analisado no estudo.

\section{RESULTADOS E DISCUSSÕES}

Neste tópico, após uma caracterização dos sujeitos da pesquisa e de seus respectivos empreendimentos hoteleiros, as demais informações extraídas nas entrevistas são apresentadas de maneira a responder aos objetivos propostos.

\subsection{Caracterização dos sujeitos da pesquisa}

Respeitando o anonimato, os oito participantes da pesquisa são apresentados pela sequência numérica em que foram entrevistados. O Quadro 1 apresenta o perfil dos sujeitos da pesquisa, como idade, grau de instrução, sexo, tempo no setor hoteleiro e no negócio específico e a função exercida nele.

No que tange a idade dos entrevistados, a maioria possui mais de 40 anos. Quanto ao grau de instrução dos entrevistados, apenas três possuem nível superior completo, um possui superior incompleto, e os demais têm até o ensino médio completo. Sobre o tempo de atuação no setor de turismo e hotelaria, quatro dos entrevistados estão no mercado há menos de 10 anos, enquanto os outros atuam há mais de 12 anos. Ainda, sobre a função que exercem em suas respectivas organizações, dos oito entrevistados, apenas um é só administrador, mas não é dono do estabelecimento; os outros sete são proprietários e administram o próprio negócio, dos quais, dois são também recepcionistas e um destes, além de proprietário e gestor, é também responsável pela manutenção da pousada. Em relação ao sexo, cinco dos entrevistados são do sexo feminino e três do sexo masculino.

Quadro 1: Perfil dos sujeitos da pesquisa, realizada no mês de junho de 2020

\begin{tabular}{|l|c|c|c|c|c|}
\hline & Idade & Grau de instrução & $\begin{array}{c}\text { Tempo no setor } \\
\text { hoteleiro }\end{array}$ & $\begin{array}{c}\text { Função na } \\
\text { organização }\end{array}$ & Sexo \\
\hline Entrevistado 1 & 40 anos & Pós Graduação & 4 anos & Administrador(a) & Feminino \\
\hline Entrevistado 2 & 61 anos & Superior Completo & 20 anos & Proprietário(a) & Masculino \\
\hline Entrevistado 3 & 57 anos & Superior Incompleto & 29 anos & Proprietário(a) & Feminino \\
\hline Entrevistado 4 & 64 anos & Ensino Médio Completo & 25 anos & Proprietário(a) & Masculino \\
\hline Entrevistado 5 & 49 anos & Ensino Médio Completo & 25 anos & Proprietário(a) & Feminino \\
\hline Entrevistado 6 & 46 anos & Superior Completo & 12 anos & Proprietário(a) & Feminino \\
\hline Entrevistado 7 & 36 anos & Ensino Médio Completo & 4 anos & Proprietário(a) & Feminino \\
\hline Entrevistado 8 & 37 anos & Ensino Médio Completo & 7 anos & Proprietário(a) & Masculino \\
\hline
\end{tabular}

Fonte: Dados da pesquisa (2020).

Quanto ao perfil dos empreendimentos, é possível verificar no Quadro 2 que, um dos estabelecimentos está classificado como quatro estrelas, quatro como três estrelas, e três estabelecimentos não apresentam nenhuma estrela. Quanto ao tipo de hospedagem, seis são pousadas e dois são hotéis. Além disso, percebe-se que a maioria dos empreendimentos funcionava 
antes da pandemia com um quadro de funcionários inferior a cinco; mas durante a pandemia, todos reduziram os seus quadros, em pelo menos um funcionário.

Quadro 2: Perfil dos empreendimentos pesquisados

\begin{tabular}{|l|c|c|c|c|}
\hline & $\begin{array}{c}\text { Classificação de } \\
\text { estrelas }\end{array}$ & Tipo de hospedagem & $\begin{array}{c}\text { No de funcionários } \\
\text { antes da pandemia }\end{array}$ & $\begin{array}{c}\text { No de funcionários } \\
\text { durante a pandemia }\end{array}$ \\
\hline Entrevistado 1 & Nenhuma & Pousada & 3 & 0 \\
\hline Entrevistado 2 & 3 estrelas & Pousada & 3 & 1 \\
\hline Entrevistado 3 & Nenhuma & Pousada & 2 & 1 \\
\hline Entrevistado 4 & 3 estrelas & Hotel & 7 & 6 \\
\hline Entrevistado 5 & 3 estrelas & Pousada & 4 & 1 \\
\hline Entrevistado 6 & 3 estrelas & Pousada & 3 & 1 \\
\hline Entrevistado 7 & 4 estrelas & Hotel & 8 & 1 \\
\hline Entrevistado 8 & Nenhuma & Pousada & 4 & 2 \\
\hline
\end{tabular}

Fonte: Dados da pesquisa (2020).

\subsection{Impacto da pandemia nos empreendimentos hoteleiros de Canoa Quabrada}

O Quadro 3 apresenta as categorias referentes ao impacto da pandemia no setor, evidenciadas pelos relatos dos informantes. Verificou-se a emergência de duas categorias principais, a incerteza que este momento trouxe; e a perda de receita, uma vez que não existe demanda. Outra categoria que se destacou refere-se às reações emocionais negativas provenientes de um despreparo emocional para lidar com momentos de crise financeira e incerteza. Tais reações se agravam por outra categoria, o descaso do Poder Público. A perda de receita, por sua vez, levou a categoria: dívidas, que se acumularam nesse período, pois sem dinheiro em caixa não é possível pagar os dividendos. Porém, um dos entrevistados tentou minimizar os impactos dessa situação com mais duas categorias: medidas impostas pelo governo e o fato de a pandemia ter acontecido em um período, até o momento, de baixa temporada e chuvoso.

Quadro 3: Impactos no setor hoteleiro causados pela pandemia, separados por categorias e seus respectivos relatos

\begin{tabular}{|c|c|}
\hline Categorias & Relatos \\
\hline $\begin{array}{l}\text { Incerteza } \\
\text { (5 relatos) }\end{array}$ & $\begin{array}{l}\text { [...] incertezas. (informações extraídas do Entrevistado 1). } \\
\text { [...] e a incerteza do futuro do negócio. (informações extraídas do Entrevistado 4). } \\
\text { [...] Não sei o que vai acontecer com o setor de turismo. (Informações extraídas do } \\
\text { Entrevistado 6). } \\
\text { [...] e nem temos previsão de reabertura. (informações extraídas do Entrevistado 7). } \\
\text { Acho que o turismo é um dos setores mais afetados nosso setor vai passar muita } \\
\text { dificuldade. Estava com planos de construção de outra pousada para o próximo ano } \\
\text { mais agora não sei quando vou poder dar início ao projeto. (informações extraídas do } \\
\text { Entrevistado 8). }\end{array}$ \\
\hline $\begin{array}{c}\text { Perda de receita } \\
\text { (5 relatos) }\end{array}$ & $\begin{array}{l}\text { O fechamento temporário das atividades é o fator mais negativo, afinal sem receita não } \\
\text { há como se manter. [...] Por isso necessitamos de aporte financeiro oferecido pelo } \\
\text { governo. (Informações extraídas do Entrevistado 2). } \\
\text { [...] nada de dinheiro. (Informações extraídas do Entrevistado 3). } \\
\text { [...] perda de cem por cento da receita. (Informações extraídas do Entrevistado 4). }\end{array}$ \\
\hline
\end{tabular}




\begin{tabular}{|c|c|}
\hline & $\begin{array}{l}\text { Receita zero. (Informações extraídas do Entrevistado 5). } \\
\text { [...] já são três meses sem entrar dinheiro. (Informações extraídas do Entrevistado 7). }\end{array}$ \\
\hline $\begin{array}{l}\text { Reações emocionais } \\
\text { negativas } \\
\text { (4 relatos) }\end{array}$ & $\begin{array}{l}\text { [...] o medo pode agravar ainda mais a situação. (Informações extraídas do Entrevistado } \\
\text { 1). } \\
\text { Stress. [...] ansiedade. [...] falta de perspectiva. [...] raiva. [...] depressão. [...] } \\
\text { (Informações extraídas do Entrevistado 3). } \\
\text { [...] o sorriso das pessoas que não vejo mais essa deixa o clima muito ruim. (Informações } \\
\text { extraídas do Entrevistado 5). } \\
\text { [...]Que nadie (ninguém - tradução nossa) está preparado para uma situação dessas. } \\
\text { (Informações extraídas do Entrevistado 6). }\end{array}$ \\
\hline $\begin{array}{c}\text { Descaso do Poder Público } \\
\text { (3 relatos) }\end{array}$ & $\begin{array}{l}\text { Acredito que se o Governo Federal tivesse coordenado desde o início, a nível de Brasil, } \\
\text { todo o processo já estaríamos trabalhando. Mas a crise política causou um aumento na } \\
\text { crise sanitária e como consequência teremos uma crise econômica, mesmo após a } \\
\text { retomada. (Informações extraídas do Entrevistado 2). } \\
\text { Pouco interesse do poder público. (Informações extraídas do Entrevistado 6). } \\
\text { O mais vergonhoso é os políticos lutando para tudo ficar pior. [...] Não dá para confiar } \\
\text { nos políticos e nem no jornalismo. (Informações extraídas do Entrevistado 8). }\end{array}$ \\
\hline $\begin{array}{l}\text { Dí } \\
\text { (2 re }\end{array}$ & $\begin{array}{l}\text { Acúmulo de dívidas. (Informações extraídas do Entrevistado 1). } \\
\text { [...] Só as contas que continuam chegando. (Informações extraídas do Entrevistado 3). }\end{array}$ \\
\hline $\begin{array}{l}\text { Inexistência de demanda } \\
\text { ( } 2 \text { relatos })\end{array}$ & $\begin{array}{l}\text { Tudo parou. O telefone não toca mais. Nada de e-mail, nada de "Zap". Pouquíssimas } \\
\text { pessoas fizeram contato ultimamente querendo saber quando iremos reabrir. Nada de } \\
\text { reservas. (Informações extraídas do Entrevistado 3). } \\
\text { A interrupção do fluxo turístico sem precedente. (Informações extraídas do Entrevistado } \\
\text { 4). }\end{array}$ \\
\hline $\begin{array}{l}\text { Impactos minimizado } \\
\text { pela sazonalidade/baixa } \\
\text { temporada/Período } \\
\text { chuvoso } \\
\text { (1 relato) }\end{array}$ & $\begin{array}{l}\text { O impacto foi grande, mas minimizado uma vez que março a junho são meses de baixa } \\
\text { temporada, quando coincide também com o período chuvoso. (Informações extraídas } \\
\text { do Entrevistado 2). }\end{array}$ \\
\hline $\begin{array}{l}\text { Impactos minimizado } \\
\text { pelas medidas do } \\
\text { governo } \\
\text { (1 relato) }\end{array}$ & $\begin{array}{l}\text { Outro fator que minimizou o impacto foram as medidas dos governos federal, estadual } \\
\text { e municipal adiando os vencimentos dos impostos para o segundo semestre. [...] } \\
\text { Impostos municipais foram adiados como IPTU [...] Imposto Federal Simples foi } \\
\text { prorrogado também. (Informações extraídas do Entrevistado 2). }\end{array}$ \\
\hline
\end{tabular}

Fonte: Dados da pesquisa (2020).

As categorias identificadas corroboram com Lafis (2020) e Gössling, Scott e Hall, (2020), quando afirmam que a pandemia do Covid-19 trouxe severas perdas para a economia, de maneira especial no setor de turismo. Posto que nesse setor, há princípios que vão em desencontro com as recomendações da OMS no cenário atual. Tais categorias também reforçam o diagnóstico de Figueira e Oosterbeek (2020), que acreditam que o setor de turismo é afetado neste momento de crise, de um lado por fatores econômicos, que sofreram perdas drásticas e, por outro, por fatores psicológicos. Bem como, com os prognósticos de Ornell et al. (2020) sobre o aumento de transtornos mentais, como ansiedade e depressão, decorrentes do medo quanto ao que virá. 


\subsection{Ações adotadas pelos empreendimentos hoteleiros de Canoa Quebrada para se adaptar ao novo cenário}

Partindo da concepção de Drucker (2016) de que o planejamento estratégico deve ser um processo contínuo, que consiste em tomar decisões (correr riscos) no presente baseadas num futuro desejado; percebeu-se que, esse cenário de incerteza, dificulta o planejamento da organização, bem como de suas ações. Assim, grande parte dos entrevistados estão adotando medidas, em sua maioria, de curto prazo, ou corretivas, visando apenas à contenção de gastos. Isso pode ser constatado no Quadro 4, posto que, sem perspectivas de retorno das atividades e se sentindo de "mãos atadas", a maioria dos informantes afirmou que suas ações atuais se resumem a reduzir custos e funcionários. Muitos estão utilizando suas reservas financeiras ou recorrendo a empréstimos bancários. Como ações, menos reativas, dois estão realizando investimento no empreendimento, reformando algumas de suas unidades e/ou fazendo pequenos reparos aguardando o retorno das atividades; enquanto, um deles manifestou que está fazendo alteração de reservas pré-pagas para períodos futuros.

Quadro 4: Mudanças atuais, separadas por categorias e seus respectivos relatos

\begin{tabular}{|c|c|}
\hline Categorias & Relatos \\
\hline $\begin{array}{l}\text { Redução de custos } \\
\text { (5 relatos) }\end{array}$ & $\begin{array}{l}\text { [...] redução de custos. [...] cortamos alguns serviços. (Informações extraídas do } \\
\text { Entrevistado } 2 \text { ). } \\
\text { [...] cortar todos os gastos desnecessários. [...] desligamos a energia elétrica. [...] Cortar } \\
\text { todos os gastos desnecessários (Informações extraídas do Entrevistado 3). } \\
\text { [...] redução de } 60 \% \text { das despesas. (Informações extraídas do Entrevistado 5). } \\
\text { [...] redução de gasto de energia, tentar usar o mínimo o dinheiro da Pousada. } \\
\text { (Informações extraídas do Entrevistado } 6 \text { ). } \\
\text { [...] estamos } 100 \% \text { fechado, só o que foi feito foi cortar os custos. [...] já vim morar na } \\
\text { pousada para cortar custos. [...] No momento estou só esperando a retomada às } \\
\text { atividades. (Informações extraídas do Entrevistado } 8 \text { ). }\end{array}$ \\
\hline $\begin{array}{l}\text { Reservas financeiras ( } 4 \\
\text { relatos) }\end{array}$ & $\begin{array}{l}\text { [...] estamos nos virando com o que conseguimos ganhar na alta temporada. } \\
\text { (informações extraídas do Entrevistado 1). } \\
\text { [...] E a sorte é que tivemos um mês de janeiro excelente, então tínhamos faturamento } \\
\text { para suportar os três meses de fechamento. (informações extraídas do Entrevistado 2). } \\
\text { Utilizando a poupança da empresa. (informações extraídas do Entrevistado 4). } \\
\text { [...] Estou usando os fundos da pousada que eram mínimos e o meus pessoais. } \\
\text { (informações extraídas do Entrevistado 6) }\end{array}$ \\
\hline $\begin{array}{c}\text { Empréstimo bancário ( } 2 \\
\text { relatos) }\end{array}$ & $\begin{array}{l}\text { [...] Solicitação de Pronampe junto ao Banco do Brasil (Aguardando). (informações } \\
\text { extraídas do Entrevistado 2). } \\
\text { Estou com as contas pagas, mas já estou vendo um empréstimo com juros baixos. } \\
\text { (informações extraídas do Entrevistado 7). }\end{array}$ \\
\hline $\begin{array}{l}\text { Investimento } \\
\text { ( } 2 \text { relatos) }\end{array}$ & $\begin{array}{l}\text { [...] uma pintura parcial, pequenas obras de reparo. (Informações extraídas do } \\
\text { Entrevistado 5). } \\
\text { Durante esse tempo que estou fechado, reformando todas as suítes e apartamentos. } \\
\text { (Informações extraídas do Entrevistado 7). }\end{array}$ \\
\hline
\end{tabular}




\begin{tabular}{|c|c|}
\hline $\begin{array}{l}\text { ução de quadro de } \\
\text { funcionários } \\
\text { ( } 2 \text { relatos) }\end{array}$ & $\begin{array}{l}\text { No momento estamos de mãos atadas, sem funcionários. (Informações extraídas do } \\
\text { Entrevistado 1). } \\
\text { [...] Utilização de medida provisória para suspensão de contrato de trabalho por } 60 \text { dias. } \\
\text { (informações extraídas do Entrevistado } 2 \text { ). } \\
\text { [...] redução de funcionários. (Informações extraídas do Entrevistado 6). } \\
\text { Foi demitido } 50 \% \text { dos colaboradores. (informações extraídas do Entrevistado 8). }\end{array}$ \\
\hline & $\begin{array}{l}\text { Tudo fechado na } \\
\text { (Informações ex }\end{array}$ \\
\hline $\begin{array}{c}\text { Adiamento de reservas (1 } \\
\text { relato) }\end{array}$ & $\begin{array}{l}\text { [...] Alteração de reservas pré-pagas para períodos futuros [...] Geração de Voucher de } \\
\text { Crédito de reservas pré-pagas que o cliente cancelou para pagamento no prazo de } 12 \\
\text { meses após o fim da pandemia, de acordo com medida provisória do Governo Federal } \\
\text { (MP-948). (informações extraídas do Entrevistado 2). }\end{array}$ \\
\hline
\end{tabular}

Fonte: Dados da pesquisa (2020).

Segundo o Sebrae (2020b), a organização que deseja sobreviver, precisa se preparar para os efeitos deste cenário e começar a se planejar para a retomada, considerando que a pandemia mudou a maneira como as pessoas reagem ao ambiente ao seu redor. Soma-se a isto, o receio e o medo, que irão direcionar as decisões dos turistas nas suas escolhas após a pandemia, e é por isso que o setor deve criar estratégias para atrair e entregar o melhor ambiente para eles. No Quadro 5 é possível identificar quais ações estão sendo planejadas para o retorno das atividades, dentre as quais pode-se destacar: políticas de preços competitivos e promoções e medidas preventivas e de higiene.

Quadro 5: Mudanças planejadas para o retorno das atividades, separadas por categorias e seus respectivos relatos

\begin{tabular}{|c|c|}
\hline Categorias & Relatos \\
\hline $\begin{array}{l}\text { Política de preços } \\
\text { competitivos e } \\
\text { promoções } \\
\text { (3 relatos) }\end{array}$ & $\begin{array}{l}\text { [...] negociamos redução de preços. (Informações extraídas do Entrevistado 2). } \\
\text { [...] estamos também preparando promoções no nosso site próprio. [...] preços } \\
\text { competitivos. (Informações extraídas do Entrevistado 4). } \\
\text { [...] pensando em fazer alguma promoção quando souber a data de reabertura. } \\
\text { (Informações extraídas do Entrevistado 8). }\end{array}$ \\
\hline $\begin{array}{l}\text { Medidas preventivas e } \\
\text { de higiene } \\
\text { ( } 2 \text { relatos) }\end{array}$ & $\begin{array}{l}\text { [...] as que estamos pensando em adotar é reforçar a higiene de tudo ainda mais. [...] } \\
\text { também restringir a quantidade de pessoas nos espaços externos. (Informações extraídas } \\
\text { do Entrevistado 1). } \\
\text { [...] álcool em gel. [...] e tem a questão da limpeza das unidades de hospedagem, tanto a } \\
\text { limpeza geral após o hóspede ir embora em definitivo, bem como a manutenção quando } \\
\text { o hóspede continuar hospedado.[...] e para iniciar faremos manutenções necessárias ao } \\
\text { bom funcionamento como, por exemplo, dedetização, jardinagem, ar condicionado, } \\
\text { sistema elétrico e de TV, basicamente. (Informações extraídas do Entrevistado } 2 \text { ). }\end{array}$ \\
\hline $\begin{array}{c}\text { Serviço de café da } \\
\text { manhã } \\
\text { (2 relatos) }\end{array}$ & $\begin{array}{l}\text { O café da manhã será servido no quarto ou respeitando um número reduzido de pessoas } \\
\text { por vez. (Informações extraídas do Entrevistado 1). } \\
\text { [...] café da manhã no quarto ou servido no salão individualmente, sem ser self-service. } \\
\text { (Informações extraídas do Entrevistado } 2 \text { ). }\end{array}$ \\
\hline $\begin{array}{c}\text { Serviços online } \\
\text { (1 relato) }\end{array}$ & $\begin{array}{l}\text { [...] estamos planejando fazer alterações em relação ao check-in, o transformando em } \\
\text { check-in online em nosso site principal, a fim de evitar que ele seja feito na recepção da } \\
\text { pousada, agilizando o check-in e evitando aglomerações. [...] vamos implementar via } \\
\text { PagSeguro link de pagamento para venda de reservas via WhatsApp. [...] e gerar um link }\end{array}$ \\
\hline
\end{tabular}




\begin{tabular}{|c|l|}
\hline & $\begin{array}{l}\text { para enviar ao cliente o formulário para preenchimento no caso de reservas feitas nas } \\
\text { OTA's e reservas no WhatsApp. (Informações extraídas do Entrevistado 2). }\end{array}$ \\
\hline $\begin{array}{c}\text { Políticas de } \\
\text { cancelamentos } \\
\text { (1 relato) }\end{array}$ & $\begin{array}{l}\text { [...] alteramos nossa política de cancelamento, o turista poderá cancelar até um dia antes } \\
\text { da chegada e ser reembolsado. (Informações extraídas do Entrevistado 2). }\end{array}$ \\
\hline $\begin{array}{c}\text { Divulgação } \\
\text { (1 relato) }\end{array}$ & $\begin{array}{l}\text { [...] divulgação em site de reservas. [...] estamos planejando fazer uma propaganda da } \\
\text { reabertura no "Google Adwords" e "Google Meu Negócio" além de contatar nossos } \\
\text { clientes cadastrados que moram na região nordeste via mala direta, uma vez que de } \\
\text { início existe a tendência de turismo apenas regional feito com veículo próprio. } \\
\text { (Informações extraídas do Entrevistado 4). }\end{array}$ \\
\hline
\end{tabular}

Fonte: Dados da pesquisa (2020).

Observa-se um comportamento defensivo ou reativo, em alguns casos analítico e pouco prospectivo dos gestores. Enfatizando que o reativo é aquele pouco flexível às mudanças do ambiente; já o prospector é aquele que enxerga nas adversidades oportunidades de maximizar os lucros (Almeida et al., 2010; Chaimankong \& Prasertsakul, 2018; Giménez, et al., 1999; Miles et al., 1978; Pletsch et al., 2015). Tendo em vista que, as ações adotadas no setor hoteleiro não diferem das de outros segmentos, seja em âmbito local ou até mesmo internacional, como amplamente é divulgado na mídia. Nada que denote um pensamento mais inovador e estratégico. Destacando um comportamento reativo, nos quais os pontos fortes e fracos não são analisados e não se enxerga oportunidades neste momento de crise.

Com exceção do Entrevistado 4 que apresenta um comportamento um pouco mais prospector, ao constatar uma tendência maior para o turismo local pós-pandemia; planeja contatar os clientes cadastrados via mala direta que moram na região Nordeste.

\section{CONCLUSÃO}

Este artigo teve como objetivo principal compreender o impacto da pandemia nos negócios de hotelaria da praia de Canoa Quebrada, bem como identificar as ações adotadas e/ou planejadas pelas organizações para se adaptar ao novo cenário e descrever sobre os efeitos, positivos e negativos, causados pelo momento de crise.

Quanto ao impacto da pandemia, observou-se que um misto de incerteza, inexistência de demanda, perda de receita e dívidas, levaram a reações emocionais negativas, agravadas pelo descaso do Poder Público. No que diz respeito às ações adotadas pelo setor para se adaptar ao novo cenário, os respondentes destacaram redução de custos e diminuição do quadro de funcionários; outros estão aproveitando a falta de movimento para investir em pequenas obras; já uma parte dos informantes relatou não estar adotando nenhuma ação, pois o momento é de incerteza. Em relação às ações que estão sendo planejadas para o retorno das atividades, os entrevistados afirmaram que estão adotando uma política de preços competitivos e promoções, medidas preventivas e de higiene, serviço de café da manhã separado, serviços online, alteração na política de cancelamento e divulgação do estabelecimento.

Em síntese, constatou-se, a partir dos relatos coletados nesta pesquisa, que os gestores estão assumindo um comportamento reativo frente ao ambiente volátil e incerto, reagindo apenas em última instância, quando forçados a tomarem decisões estratégicas; ou defensivo, mantendo 
um comportamento mais conservador; com uma minoria se posicionando de maneira analítica e pouco prospectiva, buscando alternativas para minimizar as perdas com algumas pequenas ações ou ao menos planejando ações para o futuro. Ressalta-se que, os gestores que adotam um comportamento analítico ou um pouco mais prospectivo tendem a obter um desempenho mais positivo e uma posição mais favorável no mercado em comparação aos gestores que assumem uma postura mais reativa e defensiva, conforme postulam Miles et al., (1978). Os resultados deste estudo corroboram de maneira a incentivar uma maior atenção ao comportamento estratégico adotado pelos gestores neste momento de pandemia da Covid-19, no qual o setor de turismo e hotelaria passa por drásticas mudanças.

Como alternativas para o enfrentamento da Covid-19 nesse setor, sugere-se que seus gestores estudem e monitorem o comportamento de compra de seus clientes durante e póspandemia, bem como, façam benchmarkings; não só de empresas locais, mas internacionais também; para subsidiar suas tomadas de decisões estratégicas, considerando suas particularidades, seus pontos forte e fracos e suas oportunidades e ameaças. Além disso e principalmente, recomenda-se que esses gestores transcendam o pensamento linear, e adotem técnicas de prospecção e análise de cenários futuros (Wright et al., 2009).

As limitações da pesquisa se concentram na resistência encontrada nos gestores para participar da entrevista, por se tratar de um assunto delicado, levando em consideração que muitos empreendimentos tiveram que suspender as atividades por tempo indeterminado, sendo percebido em alguns relatos sinais de angústia, raiva, insatisfação e desespero. A cerca de sugestões para trabalhos futuros, indica-se um estudo com os turistas com a finalidade de verificar a predisposição destes para viajarem pós-pandemia e as expectativas deles com relação ao setor de turismo no Brasil.

\section{REFERÊNCIAS BIBLIOGRÁFICAS}

Akron, S., Demir, E., Díez-Esteban, J. M., \& García-Gómez, C. D. (2020). Economic policy uncertainty and corporate investment: evidence from the US hospitality industry. Tourism Management, 77, 104019. https://doi.org/10.1016/j.tourman.2019.104019

Almeida, I. C., Antonialli, L. M, \& Amiralva (2010). Comportamento estratégico das mulheres empresárias: um estudo baseado na tipologia de Miles e Snow. In: Seminários em Administração - Semead, 13, São Paulo. http://sistema.semead.com.br/15semead/resultado/trabalhosPDF/129.pdf

Ariza-Montes, A, Hernández-Perlinesc, F., Hand, H., \& Lawe, R. (2019). Human dimension of the hospitality industry: working conditions and psychological well-being among European servers. Journal of Hospitality and Tourism Management, 41, 138-147. https://doi.org/10.1016/j.jhtm.2019.10.013

Bardin, L. (2006). Análise de conteúdo. Edições 70. 
Baum, T., \& Hai, N. T. T. (2020). Hospitality, tourism, human rights and the impact of COVID-19. International Journal of Contemporary Hospitality Management, 32(7), 2397-2407. https://doi.org/10.1108/IJCHM-03-2020-0242

Bertucci, J. L. O. (1999). Percepção ambiental e estratégias gerenciais em instituições de ensino superior: uma conexão improvável. In: Encontro Nacional de Pós-Graduação em Administração - Enanpad, 23, Foz do Iguaçu. http://www.anpad.org.br/admin/pdf/enanpad1999-ae-21.pdf

Brown, N. A., Rovins, J. E., Feldmann-Jensen, S., Orchiston, C., \& Johnston, D. (2017). Exploring disaster resilience within the hotel sector: a systematic review of literature. International Journal of Disaster Risk Reduction, 22, 362-370. http://dx.doi.org/10.1016/j.ijdrr.2017.02.005

Cervo, A. L., \& Bervian, P. A. (2002). Metodologia científica. Prentice Hall.

Chaimankong, M., \& Prasertsakul, D. (2019). Barriers to strategy implementation and their links with strategy typologies. Chulalongkorn Business Review, 41(3), 102-132. https://so01.tcithaijo.org/index.php/CBSReview/article/view/219286/151874

Cró, S, \& Martins, A. M. (2017). Structural breaks in international tourism demand: are they caused by crises or disasters? Tourism Management, 63, 3-9. http://dx.doi.org/10.1016/j.tourman.2017.05.009

Dahles, H., \& Susilowati, T. P. (2015). Business resilience in times of growth and crisis. Annals of Tourism Research, 51, 34-50. http://dx.doi.org/10.1016/j.annals.2015.01.002

Drucker, P. F. (2016). Inovação e espírito empreendedor: prática e princípios. Cengage Learning.

Figueira, L. M., \& Oosterbeek, L. (Coords.) (2020). Turismo mundial, crise sanitária e futuro: visões globais partilhadas [e-book]. Instituto Politécnico de Tomar. Disponível em: http://www.cda.ipt.pt/download/ebooks/CRENT-ebook-17.6.2020-turismo-crise-global-.pdf

Giménez, F. A. P., Pelisson, C., Krüger, E. G. S., \& Hayaashi, Jr., P. (1999). Estratégia em pequenas empresas: uma aplicação do modelo de Miles e Snow. Revista de Administração Contemporânea, 3(2), 53-74. https://doi.org/10.1590/S1415-65551999000200004

Gössling, S., Scott, D., \& Hall, C. M. (2020). Pandemics, tourism and global change: a rapid assessment of COVID-19. Journal of Sustainable Tourism, 1-20. https://doi.org/10.1080/09669582.2020.1758708

Henz, L. (2014). Estratégia organizacional: da escola do aprendizado às organizações que aprendem.

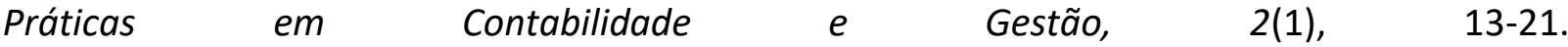
http://editorarevistas.mackenzie.br/index.php/pcg/article/view/6972/5156

Hidalgo, Á. L. N., Ramírez, D. H. B., \& Ríos, G. A. C. (2014). Estrategia organizacional: una propuesta de estudio. Estudios Gerenciales, 30(131), 153-161. http://dx.doi.org/10.1016/i.estger.2014.04.004

Instituto Brasileiro de Geografia e Estatística - IBGE. (2020). Setor de serviços tem queda recorde de 11,7\% em abril. 2020. Disponível em: https://agenciadenoticias.ibge.gov.br/agencia-sala-de- 
imprensa/2013-agencia-de-noticias/releases/27980-setor-de-servicos-tem-queda-recorde-de11-7-em-abril

Kim, M., Roehl, W., \& Lee, S. K. (2019). Effect of hotels' price discounts on performance recovery after a crisis. International Journal of Hospitality Management, 83, 74-82. https://doi.org/10.1016/j.ijhm.2019.04.006

Köseoglu, M. A., Chan, E. S. W., Okumus, F., \& Altin, M. (2019). How do hotels operationalize their competitive intelligence efforts into their management processes? Proposing a holistic model. International Journal of Hospitality Management, 83, 283-292. https://doi.org/10.1016/i.ijhm.2018.11.007

Lafis. (2020). Hotéis e turismo. Disponível em: https://www.lafis.com.br/economia/setores-daeconomia-brasileira/setor-hot\%C3\%A9is-e-turismo

Miles, R. E., Snow, C. C., Meyer, A. D., \& Coleman, Jr., H. J. (1978). Organizational strategy, structure and process. Academy of Management Review, 3(3), 546-562. https://doi.org/10.5465/amr.1978.4305755

Novelli, M., Burgess, L. G., Jones, A., \& Ritchie, B W. (2018). 'No Ebola... still doomed'-The Ebolainduced tourism crisis. Annals of Tourism Research, 70, 76-87. https://doi.org/10.1016/i.annals.2018.03.006

Oliveira, D. P. R. (2014). Estratégia empresarial \& vantagem competitiva: como estabelecer, implementar e avaliar. (9th ed.) Atlas.

Ornell, F., Schuch, J. B., Sordi, A. G., \& Kessler, F. H. P. (2020). Pandemia de medo e COVID-19: impacto na saúde mental e possíveis estratégias. Revista Debates in Psiquiatria. 2, 12-17. http://dx.doi.org/10.25118/2236-918X-10-2-2

Pletsch, C. S., Magro, C. B. D., Silva, A., \& Lavarda, C. E. F. (2015). Estratégias competitivas e desempenho econômico-financeiro de empresas brasileiras. Revista de Contabilidade $e$ Organizações, 9(25), 16-30. https://doi.org/10.11606/rco.v9i25.82709

Prodanov, C. C., \& Freitas, E. C. de. (2013). Metodologia do trabalho científico: métodos e técnicas da pesquisa e do trabalho acadêmico [recurso eletrônico]. (2nd ed.). Feevale.

Rendón, O. H. P., Martínez, R. M., \& Flores, M. S. R. (2014). Marketing strategies for hotel industry internationalization in Morelia. Procedia-Social and Behavioral Sciences, 148, 271-279. doi: http://doi.org/10.1016/j.sbspro.2014.07.043

Ritchie, B. W., \& Jiang, Y. (2019). A review of research on tourism risk, crisis and disaster management: launching the annals of tourism research curated collection on tourism risk, crisis and disaster management. Annals of Tourism Research, 79, 1-15. https://doi.org/10.1016/j.annals.2019.102812

Serviço Brasileiro de Apoio às Micro e Pequenas Empresas - Sebrae. (2020a). Pesquisa com empresários: impactos da COVID_19 nos pequenos negócios. Disponível em: 
https://bibliotecas.sebrae.com.br/chronus/ARQUIVOS CHRONUS/bds/bds.nsf/26395e8d6cdf aad19dd180ac3d994b80/\$File/19406.pdf

Serviço Brasileiro de Apoio às Micro e Pequenas Empresas - Sebrae. (2020b). Guia para o turismo em tempo de pandemia. Disponível em: https://m.sebrae.com.br/Sebrae/Portal\%20Sebrae/UFs/PE/Anexos/GuiaparaoTurismoemTem posdePandemia.pdf

Sette, I. R., \& Tomazzoni, E. L. (2017). Os desafios, as limitações e as perspectivas do modelo do índice de competitividade turística no contexto da política nacional de turismo brasileira. $\begin{array}{lllll}\text { Turismo } & - & \text { Visão } & \text { 292-318. }\end{array}$ file:///C:/Users/aline2020/Downloads/Sette Tomazzoni 2017 Os-Desafios,-as-Limitacoes-ea 45491.pdf

Siqueira, F. de S., Urano, D. G., \& Pereira, R. M. F. do A. (2017). O setor hoteleiro na praia de Canoa Quebrada/CE: Processo de expansão urbana e turística. Revista de Turismo Contemporâneo, Natal, 5(1), 23-41. https://periodicos.ufrn.br/turismocontemporaneo/article/view/7850/8532

Swaim, R. W. (2011). A estratégia segundo Drucker: estratégias de crescimento e insights de marketing extraídos da obra de Peter Drucker. LTC.

Tomé, L. M. (2018). Panorama do setor hoteleiro no Brasil. Caderno Setorial Etene, Escritório Técnico de Estudos Econômicos do Nordeste - Etene, Banco do Nordeste, Ano 3, 53, 1-13. Disponível em: $\quad$ https://www.bnb.gov.br/documents/80223/4141162/53 hoteis.pdf/97f2180f-ae959d08-b54b-a205e997ba62

Wright, P., Kroll, M. J., \& Parnell, J. (2009). Administração estratégica: conceitos. (10nd ed.). Atlas.

Zopiatis, A.; Savva, C. S.; Lambertides, N., \& Mcaleer, M. (2019). Tourism stocks in times of crisis: an econometric investigation of unexpected nonmacroeconomic factors. Journal of Travel Research, 58(3), 459-479. https://doi.org/10.1177/0047287517753998

\section{COMO CITAR ESTE ARTIGO:}

Vale, A. F. N., Regis, S. V. DA C., Santos, N. I. F. DOS, Oliveira, A. M. B. DE. (2020). O setor de hotelaria da Praia de Canoa Quebrada-CE frente a pandemia da Covid-19. Holos. 36(5), 1-16.

\section{SOBRE OS AUTORES}

\section{A. F. N. VALE}

Mestranda do Programa de Pós-Graduação em Administração da Universidade Federal Rural do Semi-Árido /Departamento de Ciências Sociais Aplicadas. E-mail: alinefrancilurdes@hotmail.com

ORCID ID: https://orcid.org/0000-0001-5876-4730

\section{S. V. DA C. REGIS}

Mestranda do Programa de Pós-Graduação em Administração da Universidade Federal Rural do Semi-Árido /Departamento de Ciências Sociais Aplicadas.

E-mail: suzanavdcr@hotmail.com

ORCID ID: https://orcid.org/0000-0002-0282-8296

\section{N. I. F DOS SANTOS}


Mestranda do Programa de Pós-Graduação em Administração da Universidade Federal Rural do Semi-Árido /Departamento de Ciências Sociais Aplicadas. E-mail: natalyinez@gmail.com ORCID ID: https://orcid.org/0000-0001-9171-8111

\section{A. M. B. DE OLIVEIRA}

Doutora em Psicologia Social e Antropologia das Organizações/ Departamento de Ciências Sociais Aplicadas. E-mail: agostinhamafalda@ufersa.edu.br

ORCID ID: https://orcid.org/0000-0002-6055-1758

Editor(a) Responsável: Francinaide de Lima Silva Nascimento Pareceristas Ad Hoc: Marcelo Taveira, Gerson Nascimento e lone Morais

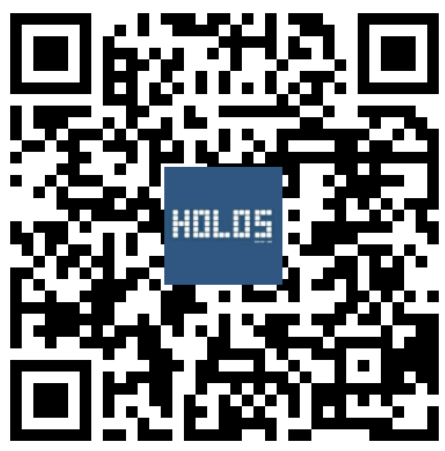

